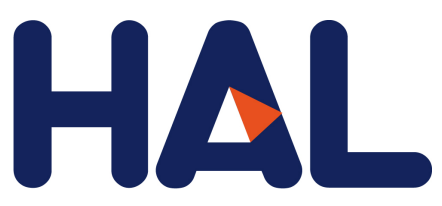

archives-ouvertes

\title{
Surface and porous textural properties of silica-wollastonite composites prepared by sol-gel process
}

Lismarihen Larreal de Hernandez, Liz Anez-Borges, Thierry Woignier, Adil

Alaoui, Sylvie Calas-Etienne, Florence Despetis, Laurent Bonnet, Bruno

Colaiocco, Said Tahir, Philippe Dieudonne-George

\section{To cite this version:}

Lismarihen Larreal de Hernandez, Liz Anez-Borges, Thierry Woignier, Adil Alaoui, Sylvie CalasEtienne, et al.. Surface and porous textural properties of silica-wollastonite composites prepared by sol-gel process. Journal of Sol-Gel Science and Technology, Springer Verlag, 2019, 90 (1), pp.113-125. 10.1007/s10971-018-4874-9 . hal-02464294

\section{HAL Id: hal-02464294 \\ https://hal.archives-ouvertes.fr/hal-02464294}

Submitted on 3 Feb 2020

HAL is a multi-disciplinary open access archive for the deposit and dissemination of scientific research documents, whether they are published or not. The documents may come from teaching and research institutions in France or abroad, or from public or private research centers.
L'archive ouverte pluridisciplinaire $\mathbf{H A L}$, est destinée au dépôt et à la diffusion de documents scientifiques de niveau recherche, publiés ou non, émanant des établissements d'enseignement et de recherche français ou étrangers, des laboratoires publics ou privés. 




\title{
Surface and porous textural properties of silica-wollastonite composites prepared by sol-gel process
}

\author{
Lismarihen Larreal de Hernandez ${ }^{1} \cdot$ Liz Anez-Borges $^{1} \cdot$ Thierry Woignier $^{2,3} \cdot$ Adil Hafidi Alaoui $^{4}$.

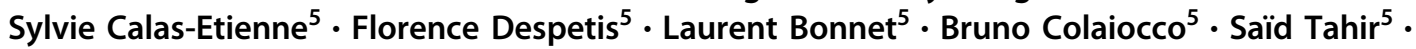 \\ Philippe Dieudonné-George $\mathbb{1}^{5}$
}

\begin{abstract}
Silica-wollastonite xerogel composites (xerocomposites) with different wollastonite filler content were obtained after classical drying of silica-wollastonite gels. Two different silica precursors were used, TEOS and colloidal LUDOX, for composites named TW and LW, respectively. We utilized SAXS experiments, $\mathrm{N}_{2}$ adsorption-desorption, and SEM techniques to determine the textural and structural properties of these porous materials. For both the TW and LW composites, it was shown that a macroporosity and a mesoporosity coexist. We argue that the proportion of macroporosity directly depends on the proportion of wollastonite fillers in the composite. We propose a unique two-stage drying mechanism to explain the formation of macropores. We additionally found that the surface of wollastonite fillers was covered by a dense multilayer packing of silica colloids in LUDOX LW xerocomposites. We believe that these surfacemodified wollastonite fillers could improve the carbonation kinetics of wollastonite when used as a precursor for aqueous mineral carbonation, a promising route for safe and durable carbon sequestration.
\end{abstract}

\section{Graphical Abstract}

SEM image of wollastonite fillers covered by silica in a LUDOX-wollastonite composite (left), and schematic representation of the dense coating of colloidal silica particles at the surface of wollastonite fillers in LUDOX-wollastonite composites (right)
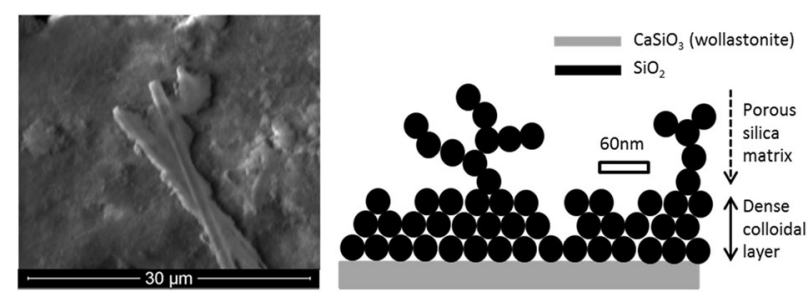

Philippe Dieudonné-George

philippe.dieudonne-george@umontpellier.fr

1 Departamento de Física, Facultad de Ingeniería, Universidad del Zulia-Venezuela, Zulia, Venezuela

2 Université Aix Marseille, Université d'Avignon, CNRS, IRD, IMBE, Marseille, France
Institut Méditerranéen de Biodiversité et d'Ecologie, Campus Agro Environnemental Caraïbes, Le Lamentin, France

4 Laboratoire Génie civil et Mécanique, Université Abdelmalek Essaâdi, Faculté des Sciences et Techniques, Tanger, Morocco

5 Laboratoire Charles Coulomb (L2C), Univ. Montpellier, CNRS, Montpellier, France 


\section{Highlights}

- Silica-wollastonite xerogel-composites (xerocomposites) were prepared.

- TEOS-wollastonite and LUDOX-wollastonite xerogels show porosity at two different scales, a macroporosity and a mesoporosity as confirmed from macroscopic and $\mathrm{N}_{2}$ adsorption-desorption measurements.

- SAXS, SEM, and $\mathrm{N}_{2}$ adsorption-desorption measurements reveal that the wollastonite filler surface is covered by a dense coating of silica colloidal particles in LUDOX-wollastonite xerocomposites.

Keywords Sol-gel materials $\cdot$ Silica-wollastonite xerocomposite $\cdot$ SAXS $\cdot$ Gas adsorption-desorption $\cdot$ Mineral carbonation - Carbon dioxide sequestration

\section{Introduction}

Silica xerogels and aerogels are fascinating materials due to their unique physical properties, such as large specific surface area (SSA), low bulk density, high porosity, high sorption capacity, very high thermal shock resistance, insolubility in most solvents, and lower index of refraction compared to other inorganic gels [1-3]. They are thus interesting materials for both technological applications and theoretical research owing to the originality of their fractal structure [4]. They have been studied for many applications, including catalyst supports [5], insulators [6], acoustic materials [7], cosmic dust captors [8], chromatography, drug delivery and ion exchange [9, 10], silicate glasses [11] and as host matrices for chemical species [12] or nuclear waste storage [13].

The most attractive features of silica gels are their tailored textural and structural properties. In sol-gel processing, structural properties can be easily tuned by changing various parameters, such as $\mathrm{pH}$, precursor/solvent molar ratio, hydrolysis, and condensation rates [14]. These properties make gels attractive materials especially for use in adsorption, capture, and sequestration of pollutant gases [15].

$\mathrm{CO}_{2}$ is the main greenhouse gas that contributes to climate change and causes global warming. Currently, one of the main strategies for the long-term storage of $\mathrm{CO}_{2}$ is the design of materials based on carbonation reactions. Mineral carbonation is a relatively new and less explored chemical storage route in which $\mathrm{CO}_{2}$ is stored as a mineral carbonate, a stable product that is environmentally friendly. The guiding concept of mineral carbonation is to imitate the natural process known as weathering. For the particular purpose of $\mathrm{CO}_{2}$ fixation, the addition of an active divalent cation silicate, such as wollastonite, is necessary to promote the $\mathrm{CO}_{2}$ speciation and its subsequent capture via carbonation reactions of $\mathrm{CaSiO}_{3}$ to a stable calcite $\left(\mathrm{CaCO}_{3}\right)$ solid $[16,17]$. Dissolution of Wollastonite in aqueous solution is the result of an incongruent process which induces the release of $\mathrm{Ca}^{2+}$ cations and the formation of a Si-rich leached layer $\left(\mathrm{SiO}_{2}\right)$ at the surface of wollastonite grains [18]. The solubility of wollastonite is low $(0.095 \mathrm{~g} / \mathrm{l})$ in water at neutral $\mathrm{pH}$, favored in acid media $(\mathrm{HCl})$, but the rate of $\mathrm{Ca}^{2}$ + release $\left(9.09 \times 10^{-9} \mathrm{~mol} / \mathrm{m}^{2} \mathrm{~s}\right)$ was shown to be independent of $\mathrm{pH}$ when ranging between 2 and 6 [18]. The growth of calcite crystals takes place at the surface of wollastonite grains, at a $\mathrm{pH}$ close to 7 , resulting from the reaction of $\mathrm{Ca}^{2+}$ cations and dissolved $\mathrm{CO}_{2}$, in the form of bicarbonate ions $\left(\mathrm{HCO}_{3}{ }^{-}\right)$. Such a mechanism induces the formation of a dense calcite layer, whose thickness increases with the continuation of the carbonation process. The calcite layer was shown to be a barrier to diffusion of $\mathrm{Ca}^{2+}$ cations, which then induces a significant decrease of carbonation kinetics $[19,20]$. Calcite crystallization during the carbonation of wollastonite is then obtained by heterogeneous nucleation. The surface of wollastonite grains plays a critical role in crystallization because nucleation sites are favored there. Modification of the surface roughness of wollastonite grains could then favor germination and growth kinetics of calcite crystallization. Embedding calcium silicate (wollastonite, $\mathrm{CaSiO}_{3}$ ) grains inside a porous silica matrix (with TEOS as silica precursor) was revealed to be a way of enhancing carbonation efficiencies, even at ambient pressure and temperature [21-23]. We believe that the silica matrix modifies the wollastonite surface roughness and surface chemical nature. Such changes could better explain the role of the silica matrix as a catalyst for the carbonation reaction of wollastonite. Our interest is to provide low cost silica-wollastonite composites for efficient wollastonite carbonation, avoiding aerogel synthesis (obtained after thermal treatment), and using low cost natural wollastonite fillers as a raw material.

In this work, we used the sol-gel process to prepare silica-wollastonite $\left(\mathrm{SiO}_{2}-\mathrm{CaSiO}_{3}\right)$ porous xerogel composites (xerocomposites), where wollastonite fillers are embedded in a silica porous matrix. We expect that the surface shape and roughness of wollastonite grains could be modified at the nanometer scale during the sol-gel synthesis, with surface changes depending of the nature of the silica precursor (colloidal or molecular). The chemical surface of wollastonite fillers is covered by silanol $\equiv \mathrm{Si}-\mathrm{OH}$ groups, and in the sol, the silica precursors can also react and condense at the surface of the fillers, thus modifying the 


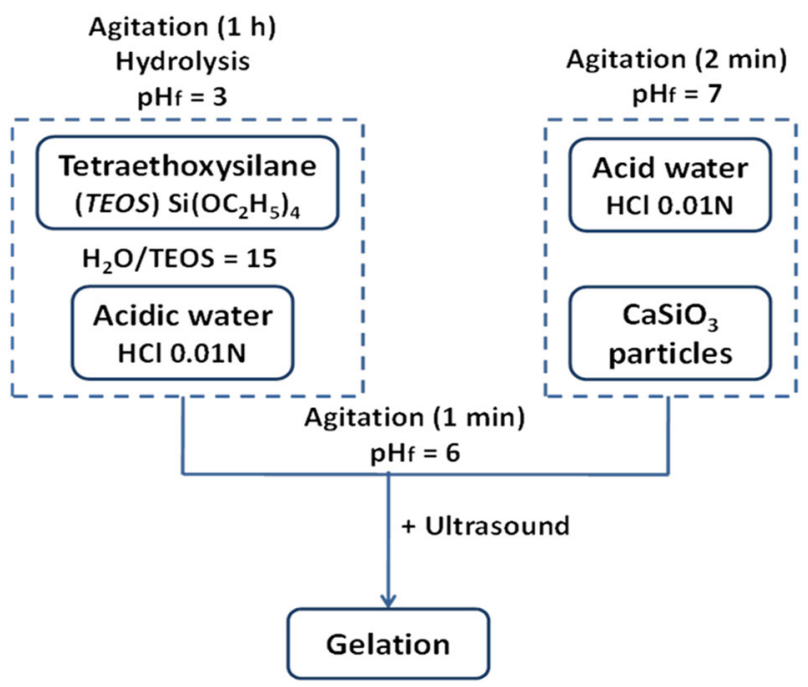

Fig. 1 Schematic representation of $\mathrm{SiO}_{2}-\mathrm{CaSiO}_{3}$ composite gel synthesis using the organic precursor (TEOS)

chemical nature and roughness of the wollastonite grains surface.

In the present study, the textural (surface roughness, pore volume, pore size distribution) and structural (surface chemical nature, size of silica primary particles, fractal structure of silica clusters) of our $\mathrm{SiO}_{2}-\mathrm{CaSiO}_{3}$ xerocomposites were investigated by using small angle X-ray scattering (SAXS), scanning electron microscopy (SEM), and $\mathrm{N}_{2}$ adsorptiondesorption techniques. The objective of this study is a better understanding of the influence of different factors, such as the drying process, the filler content, and the precursor type (colloidal or molecular) on the porous and surface texture of our xerocomposites.

\section{Experimental}

Two types of composite gels $\mathrm{SiO}_{2}-\mathrm{CaSiO}_{3}$ were prepared, using two different silica precursors, (i) a molecular one, tetraethyl orthosilicate (TEOS) and (ii) a colloidal solution (LUDOX TM50). For both protocols, the molar ratios $\mathrm{SiO}_{2}$ : $\mathrm{CaSiO}_{3}$ were 8:0 (pure silica gel), 8:1, 8:2, and 8:4. The amount of silica was kept constant for all composite gels, where only the wollastonite amount was adjusted depending of the molar ratio $\mathrm{SiO}_{2}-\mathrm{CaSiO}_{3}$.

\subsection{Composite-gels synthesis using the organic precursor (TEOS)}

The synthesis protocol was inspired by the one proposed by Primera [24] which is shown in Fig. 1. Firstly, the mixture of $10.8 \mathrm{ml} \mathrm{HCl} 0.01 \mathrm{M}$ and $8.92 \mathrm{ml}$ TEOS was mechanically agitated in order to achieve the miscibility of these compounds, during which hydrolysis was carried out. In order to obtain a complete hydrolysis, an over-stoichiometric ratio $\mathrm{H}_{2} \mathrm{O}$ :TEOS $\approx 15$ was used. Secondly, natural wollastonite particles $\left(\mathrm{CaSiO}_{3} \mathrm{Kemolit}^{\circledR} \mathrm{k} 1010\right)$ were dispersed in $\mathrm{H}_{2} \mathrm{O}(10.8 \mathrm{ml} \mathrm{HCl} 0.01 \mathrm{M})$ through mechanical agitation, to obtain $\mathrm{H}_{2} \mathrm{O}$-mineral solutions with various wollastonite contents $(0 ; 0.58 ; 1.16$ and $2.32 \mathrm{~g}$, respectively). During the 2 min mechanical agitation step, the $\mathrm{pH}$ of wollastonite particles in the solution was observed to increase from 2 to 7 , because of the alkaline character of wollastonite in aqueous media. When a wollastonite powder is introduced in a neutral $\mathrm{pH}$ aqueous solution, its $\mathrm{pH}$ was observed to increase rapidly to a value between 9 and 10 . During our synthesis process, wollastonite fillers were then exposed to an acidic media $(\mathrm{HCl}, 0.01 \mathrm{M})$ during a few seconds $(<2 \mathrm{~min})$. The incongruent dissolution rate remains very low as mentioned in the Introduction, even at this low $\mathrm{pH}$, and the dissolved quantity remains negligible as shown by other authors [18] who proposed a relation (1) which evaluates the thickness $x$ (m) of the leached Si reach layer at the wollastonite surface, during its dissolution, as a function of hydrogen ions concentration $\left[\mathrm{H}^{+}\right]\left(\mathrm{mol} \times \mathrm{l}^{-1}\right)$ and time $t(\mathrm{~s})$.

$x=1.19 \times 10^{-9}\left[\mathrm{H}^{+}\right]^{0.121} t^{0.412}$

Using relation (1) we found that for $t=120 \mathrm{~s}$, the thickness ranges between 1.2 and $4.9 \mathrm{~nm}$ for a $\mathrm{pH}$ varying from 2 to 7 during this 2 min period. Thus, we consider that the dissolution of our micron-sized wollastonite fillers can be neglected during this time window.

Next, to obtain the composite gels, the $\mathrm{H}_{2} \mathrm{O}-$ TEOS and $\mathrm{H}_{2} \mathrm{O}$-mineral solutions were mixed through mechanical agitation (final $\mathrm{pH}=6$ ). In order to favor gelation of pure TEOS solution, a basic solution $\left(0.17 \mathrm{M} \mathrm{NH}_{4} \mathrm{OH}\right)$ was added until the mixed solution reaches a pH between 5 and 6. Finally, ultrasonication (via an ultrasonic bath) was applied until gelation was achieved in order to avoid decantation of mineral particles. The fast gelation $(3 \mathrm{~min})$ prevents the mineral particles' decantation in the suspension and also provides homogeneous gels. The gelation was done at room temperature in sealed test tubes.

\subsection{Composite-gel synthesis using the mineral precursor (LUDOX)}

The synthesis protocol is shown in Fig. 2. In the first stage, depending on the desired $\mathrm{SiO}_{2}-\mathrm{CaSiO}_{3}$ molar ratio of the gel, the appropriate amount $(0 ; 0.58 ; 1.16$ and $2.32 \mathrm{~g}$ respectively) of natural wollastonite particles $\left(\mathrm{CaSiO}_{3}\right.$ Kemolit $^{\circledast}$ k1010) was added under mechanical agitation to $14.4 \mathrm{ml}$ of a $\mathrm{NaCl}$ solution $1.25 \mathrm{M}$ (with final $\mathrm{pH}=8$ ). Then, $4.8 \mathrm{ml}$ of LUDOX (TM-50, colloidal suspension 50\% 


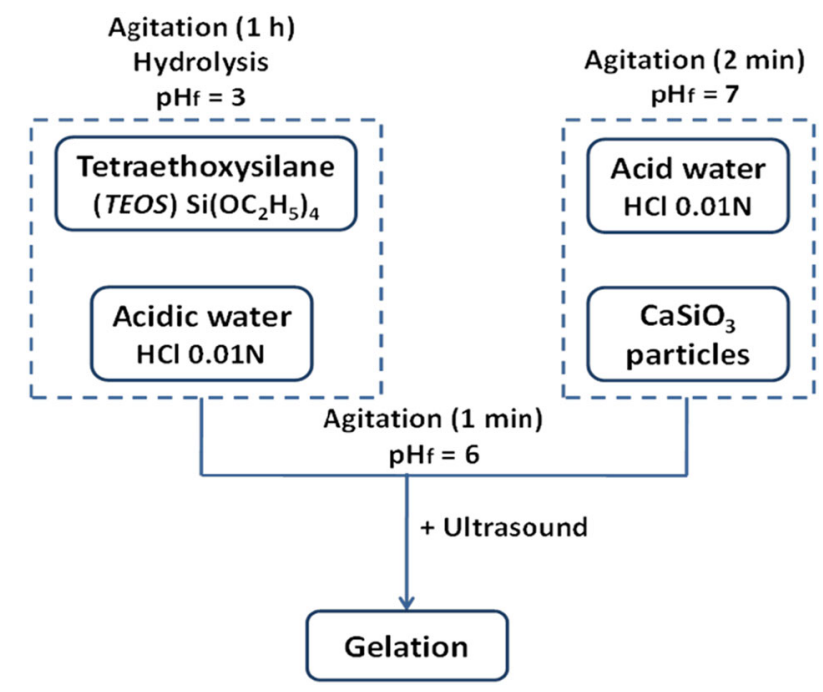

Fig. 2 Schematic representation of $\mathrm{SiO}_{2}-\mathrm{CaSiO}_{3}$ composite gel synthesis using the mineral precursor (LUDOX)

a)

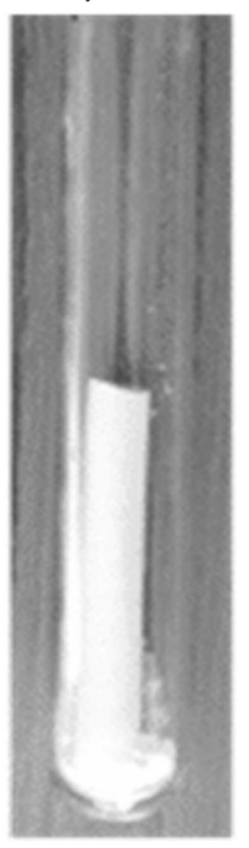

Fig. 3 Photos of a TW8:2 xerocomposite and b LW8:2 xerocomposite in sealed tubes

$\mathrm{SiO}_{2}$ in water, Sigma-Aldrich, with particle diameter of 30 $\mathrm{nm}$ ) was mixed into the solution, maintaining mechanical agitation for $1 \mathrm{~min}$. We applied ultrasonication until the gelation was rapidly achieved, in order to prevent the decantation of the mineral particles. The quantity of $\mathrm{NaCl}$ in the sol was optimized in order to obtain gels of homogeneous composition after only $2 \mathrm{~min}$. The gelation was carried out at room temperature in sealed test tubes.

\subsection{Xerocomposites $\mathrm{SiO}_{2}-\mathrm{CaSiO}_{3}$}

In our study, silica (T for TEOS and L for LUDOX)-wollastonite (W) xerogels are labeled by their $\mathrm{SiO}_{2}: \mathrm{CaSiO}_{3}$ molar fraction: TW8:0, TW8:1, TW8:2, TW8:4 (xerocomposites with TEOS as silica precursor) and LW8:0, LW8:1, LW8:2, LW8:4 (xerocomposites with LUDOX silica precursor).

Composite LW and TW gels were then aged for 7 days where a slight macroscopic shrinkage (syneresis) was observed, indicating the continuation of condensation reactions and strengthening of the silica network during the ageing period [1]. To obtain xerocomposites, slow drying of gels ( 15 days) was performed at $80^{\circ} \mathrm{C}$, in their sealed tubes slightly opened. Gels exhibit an important macroscopic volume shrinkage during the drying step [1] with a total diameter decrease to around $42 \%$ and $25 \%$ for TW and LW xerocomposites, respectively, as shown in Fig. 3. This difference of macroscopic shrinkage could be explained by the higher quantity of liquid phase in the TW compared to LW composite gels. The TW gels are therefore more diluted. After the drying step, both LW and TW xerogels exhibit about the same apparent density of around $0.6 \mathrm{~g} / \mathrm{cm}^{3}$.

\subsection{Sample characterization}

The Brunauer, Emmett and Teller (BET)-SSA and the Barrett, Joyner and Halenda $(\mathrm{BJH})$ pore volume and pore size distribution of our composite xerogels were measured, using an $\mathrm{N}_{2}$ adsorption-desorption technique. The measurements were performed with a micromeritics sortometer, model ASAP2020 , using nitrogen at $77 \mathrm{~K}$ as gas for the analysis. The outgassing takes place during a period of $24 \mathrm{~h}$ at $70^{\circ} \mathrm{C}$ with a vacuum of $2-4 \mu \mathrm{m} \mathrm{Hg}$. Type IV isotherms with hysteresis at desorption were observed (not shown) for all TW and LW samples, as expected for mesoporous materials.

As shown in previous studies [25-29], the porous texture of some composite-silica-filler-dried gels can present porosity at two different scales: meso and macroporosity. In this work, for better clarity in our discussions, we have considered that mesopores correspond to pore diameters ranging from 2 to $100 \mathrm{~nm}$, which differs from IUPAC nomenclature $(2-50 \mathrm{~nm})$. As a consequence, macropores correspond to pores whose diameter is larger than $100 \mathrm{~nm}$ (instead of $50 \mathrm{~nm}$ as specified by IUPAC). The proportion of mesoporous and macroporous volume of our TW and LW composites will be evaluated by combining two different measurements. Firstly, BJH total mesoporous volume expressed in $\mathrm{cm}^{3}$ per gram of $\mathrm{SiO}_{2}$ will allow evaluation of the mesoporous volume $\left(V_{\mathrm{m}}\right)$ in our composite xerogels. Secondly, from the measured volume, the weight of dried monoliths xerogel, and the solid phase density $\left(\rho_{\mathrm{s}}\right)$, we deduced an apparent density $\left(\rho_{\mathrm{a}}\right)$ of monoliths composite that can determine the total pore volume $\left(V_{\mathrm{T}}\right)$ in $\mathrm{cm}^{3}$ per 
gram of $\mathrm{SiO}_{2}$. The macroporous volume $\left(V_{\mathrm{M}}\right)$, (in $\mathrm{cm}^{3}$ per gram of $\mathrm{SiO}_{2}$ ) will then be deduced from both $V_{\mathrm{m}}$ and $V_{\mathrm{T}}$, considering relation (2):

$$
V_{\mathrm{M}}=V_{\mathrm{T}}-V_{\mathrm{m}}
$$

The SSA $\left(\mathrm{m}^{2} / \mathrm{g}\right)$, pore volumes $\left(\mathrm{cm}^{3} / \mathrm{g}\right)$, and pore volume distribution $\left(\mathrm{cm}^{3} / \mathrm{g}\right)$ obtained by the BET and BJH method are usually given as a function of the weight of the total solid phase (which contains both the $\mathrm{SiO}_{2}$ and $\mathrm{CaSiO}_{3}$ phases in our composites). The size of wollastonite particles $(\mu \mathrm{m})$ is larger compared those of silica particles $(\mathrm{nm})$. The main contribution to the surface area and mesoporous volume in our composites should then be mainly due to the silica phase. The contribution of wollastonite particles to the surface area and mesoporous volume of the composite can then be neglected (pure wollastonite BET SSA was found to be $1.79 \mathrm{~m}^{2} / \mathrm{g}$ ). In order to compare results obtained from BET SSA and BJH analysis for xerocomposites with constant $\mathrm{SiO}_{2}$ content but various $\mathrm{CaSiO}_{3}$ contents, we found it more interesting and appropriate to present BET and BJH analysis as a function of the weight $(\mathrm{g})$ of $\mathrm{SiO}_{2}$ only. For our calculations, the skeletal density of the silica phase in our TW and LW xerogels was estimated to be $2 \mathrm{~g} / \mathrm{cm}^{3}$. This value, lower than $2.2 \mathrm{~g} / \mathrm{cm}^{3}$ (amorphous silica), was reported for sol-gel silica, especially when the synthesis was performed without thermal nor oxidation treatment [30].

SAXS experiments were performed on xerocomposite powders with an in-house setup. A high brightness low power $\mathrm{X}$ - ray tube, coupled with an aspheric multilayer optic (GeniX ${ }^{3 \mathrm{D}}$ from Xenocs) was employed. It delivers an ultralow divergent beam $(0.5 \mathrm{mrad}, \lambda=0.15418 \mathrm{~nm})$. Scatterless slits were used to give a clean $0.6 \mathrm{~mm}$ beam diameter with a flux of $35 \mathrm{Mphotons} / \mathrm{s}$ at the sample. We worked in a transmission configuration and scattered intensity was measured by a 2D "Pilatus" $300 \mathrm{~K}$ pixel detector by Dectris $\left(490 * 600\right.$ pixels) with pixel size of $172 \times 172 \mu \mathrm{m}^{2}$, at a distance of $1.9 \mathrm{~m}$ from the sample. All Intensities $I(q)$ are expressed as a function of the wave vector $q\left(\mathrm{~nm}^{-1}\right)$ and corrected by transmission. The empty cell and the low wollastonite filler contributions were substracted. SAXS patterns were fitted using the SASfit software [31].

Scanning electronic microscopy measurements were performed with a FEI INSPECT S50 apparatus in a high vacuum mode, at $12.5 \mathrm{kV}$.

\section{Results and discussion}

\subsection{Optical microscopy imaging}

Our xerocomposites contain two solid phases with different textural and structural properties. The silica network obtained after the gelification process is made of nanometric

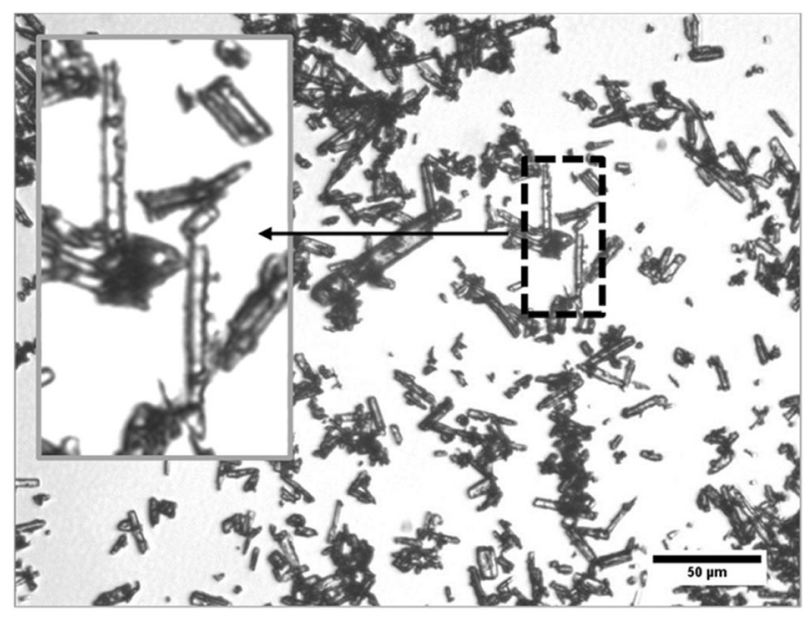

Fig. 4 Optical microscopy image of wollastonite filler

primary particles, while wollastonite fillers are rod-like particles with an average size of about $5 \times 20 \mu^{2}$, as observed by optical microscopy (Fig. 4). Smaller particles with sizes lower than $1 \mu \mathrm{m}$ can be observed. They can contribute to an intensity contribution in SAXS measurements. The wollastonite powder SAXS intensity was then measured (not shown). We estimated that its contribution to the total SAXS intensity of silica-wollastonite xerocomposites could be neglected.

\subsection{SAXS measurements on TW and LW xerogels}

The SAXS patterns of TW xerogels are shown in Fig. 5.

SAXS profiles can give us information on the size of the primary particles (in the $\mathrm{nm}$ scale) forming the silica network. A model based on connected string of spherical pearls was chosen (with a radius polydispersity of $25 \%$ ) in order to fit experimental results and find the average radius of primary spherical particles as indicated in Fig. 5. We can clearly observe that silica particles are smaller in pure TW8:0 silica xerogel $\left(r_{1}=3 \pm 0.1 \mathrm{~nm}\right)$, compared to TW8:2 silica xerocomposite containing wollastonite $\left(r_{2}=\right.$ $5.3 \pm 0.1 \mathrm{~nm}$ ). The same larger radius value was measured for all TW xerocomposite regardless of the wollastonite content. We can consider that the addition of wollastonite fillers in the sol modifies ionic forces induced by the alkaline properties of wollastonite in water. A modification of ionic forces in the sol could then influence the hydrolysispolycondensation mechanisms of TEOS at the beginning of the gelification process, thus creating larger primary silica particles in composite gels compared to those obtained in pure silica gels.

SAXS patterns of LW xerogels are represented in Fig. 6.

For LW samples, SAXS results (Fig. 6) show that primary silica particles have a radius of $15 \mathrm{~nm}$, and four oscillations clearly observed indicate a low size 


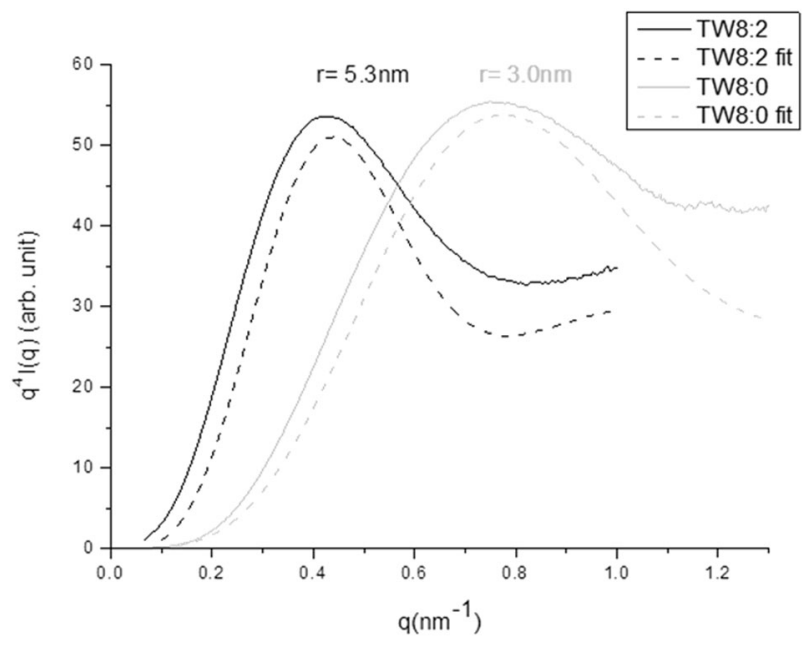

Fig. 5 Representation $q^{4} I(q)=f(q)$ of SAXS pattern for TW8:0 and TW8:2 xerogels. Dotted lines correspond to fit of experimental data to obtain the radius $r$ of primary silica particles

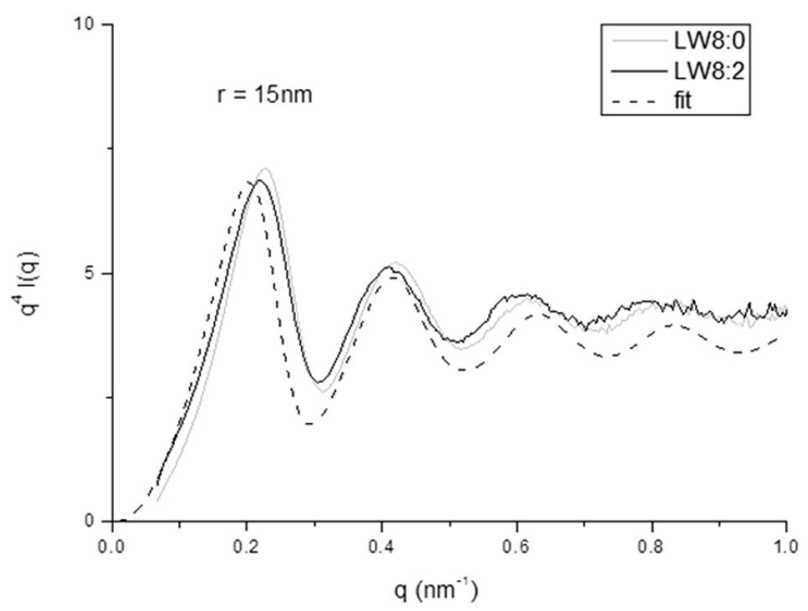

Fig. 6 Representation $q^{4} I(q)=f(q)$ of SAXS pattern for LW8:0 and LW8:2 xerocomposites. Dotted line correspond to fit of experimental data to obtain the radius $r=15 \mathrm{~nm}$ of primary silica particles

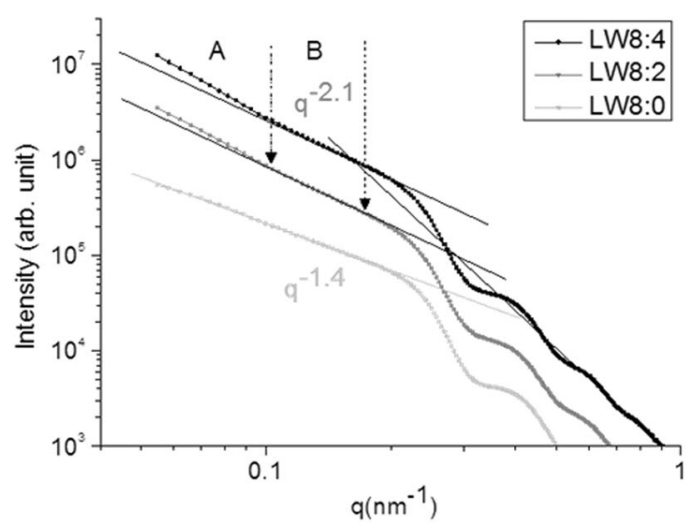

polydispersity $(\sim 14 \%)$. As expected, the size of LUDOX primary-colloidal-particles remains constant during the entire gelification and drying process, regardless of the presence of wollastonite fillers in the sol. SAXS patterns of both LW8:0; LW8:2; LW8:4 and TW8:0; TW8:2; TW8:4 series of xerogels are shown in a $\log -\log$ scale in Fig. 7. Scattered intensities are shifted for better clarity.

For LW8:0 sample (Fig. 7, left), at low $q$ range, $I(q)$ vary with $q^{-1.4}$ in a large $q$ range. This result is consistent with large fractal silica clusters. The 1.4 exponent indicates the existence of mass fractal clusters with fractal dimension of 1.4. For LW8:2 and LW8:4 samples, two distinct domains (A and B) can be defined (Fig. 7, left). In the B domain, a $q$ ${ }^{-2.1}$ fractal regime is observed. The same exponent of 2.1 is observed regardless of the filler content, and is higher than the one obtained for the pure LUDOX LW8:0. The B-fractal domain covers a narrow $q$ range of $\sim 0.1-0.2 \mathrm{~nm}^{-1}$. We believe that this higher exponent for $\mathrm{LW}$ xerocomposites can be related to surface fractal silica clusters with fractal dimension of 2.1 [32]. In the A domain (Fig. 7, left), a distinct regime is observed at the lowest $q$ values. The observed intensity increase can be related to scattering from larger secondary silica clusters.

In the case of the TW samples, pure TEOS xerogel (TW8:0) exhibits a non-fractal structure (homogeneous porous structure of silica clusters), as indicated by the $q^{0}$ regime at low $q$ values (Fig. 7, right). The existence of a $q$ ${ }^{-1.1}$ fractal regime (B domain) at low $q$ for all TW xerocomposites can be attributed to a mass fractal structure of silica clusters with a fractal dimension of 1.1. As mentioned in the discussion, the existence of wollastonite in the sol can modify the primary particles growth and aggregation mechanisms in TEOS-wollastonite gels, giving larger primary silica particles and fractal silica clusters in all TW xerocomposites compared to non-fractal pure TEOS xerogel. In the A domain, a second regime is observed at the lowest $q$ values. It can be related (like in LW xerocomposites) to scattering from larger secondary clusters.

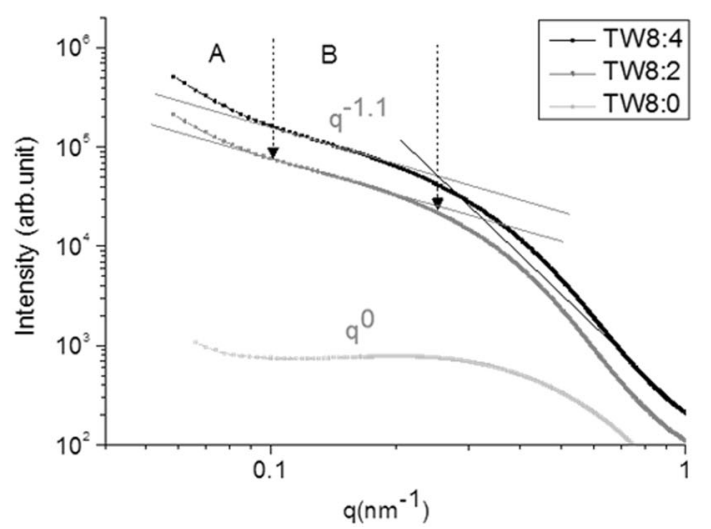

Fig. 7 SAXS pattern of LW8:0, LW8:2, and LW8:4 (left) and TW8:0, TW8:2, and TW8:4 (right) 
Table 1 Measured BET SSA $\left(\mathrm{m}^{2} / \mathrm{g}\right)$ and calculated SSA $\left(\mathrm{m}^{2} / \mathrm{g}\left(\mathrm{SiO}_{2}\right)\right)$ of LW and TW composite samples, for different molar ratio $\mathrm{SiO}_{2}$ : $\mathrm{CaSiO}_{3}$

\begin{tabular}{lll}
\hline $\begin{array}{l}\text { Xerogel } \\
\text { sample }\end{array}$ & $\begin{array}{l}\text { Measured BET SSA } \\
\left(\mathrm{m}^{2} / \mathrm{g}\right)( \pm 5 \%)\end{array}$ & $\begin{array}{l}\text { Calculated BET SSA }\left(\mathrm{m}^{2} /\right. \\
\left.\mathrm{g}\left(\mathrm{SiO}_{2}\right)\right)( \pm 5 \%)\end{array}$ \\
\hline TW8:0 & 294 & 294 \\
TW8:1 & 133 & 166 \\
TW8:2 & 113 & 171 \\
TW8:4 & 87 & 174 \\
LW8:0 & 75 & 75 \\
LW8:1 & 62 & 77 \\
LW8:2 & 52 & 78 \\
LW8:4 & 35 & 70 \\
\hline
\end{tabular}

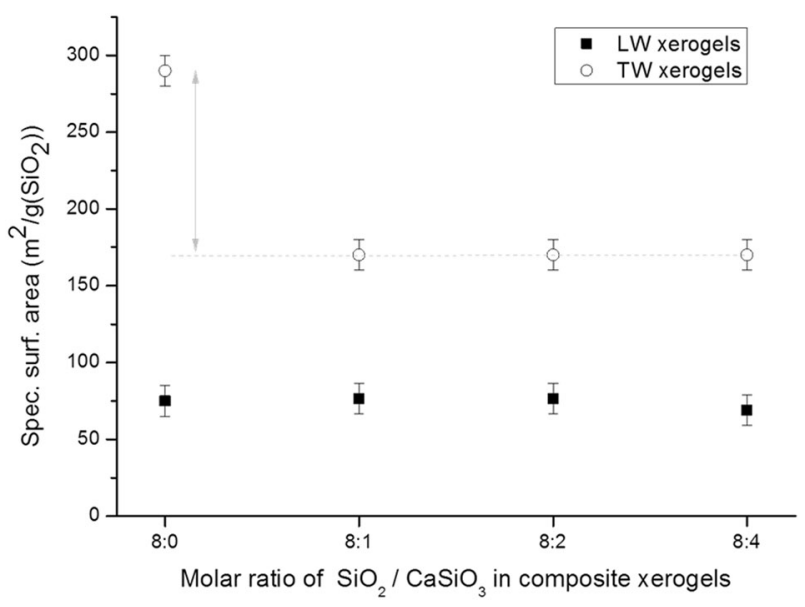

Fig. 8 Evolution of the Specific surface area in $\mathrm{m}^{2}$ per $\mathrm{g}$ of $\mathrm{SiO}_{2}$, as a function of the molar ratio $\mathrm{SiO}_{2}: \mathrm{CaSiO}_{3}$ in in $\mathrm{LW}$ and TW xerogels

For all silica-wollastonite xerocomposites, from the $q$ value $\left(\sim 0.1 \mathrm{~nm}^{-1}\right)$ obtained from to the low $q$ limit of the fractal regime (limit between the $\mathrm{A}$ and $\mathrm{B}$ domain), we can evaluate the size $\xi$ of the silica fractal clusters [33, 34]. We obtain $\xi \sim 2 \pi / 0.1 \sim 60 \mathrm{~nm}$. This size is only $2-6$ times larger than the diameter of primary silica particles $(30$ and $10.6 \mathrm{~nm}$ for LW and TW, respectively). It indicates a fractal character with small fractal domains in all our LW and TW xerocomposites. SAXS results are also in accordance with the existence of larger secondary silica clusters, which could be separated by macropores in xerocomposites. These secondary clusters can be constituted of aggregates of $\sim 60 \mathrm{~nm}$ primary-fractal clusters.

\subsection{Surface properties of TW and LW xerogels}

Table 1 and Fig. 8 show measured SSA values and calculated SSA values expressed as a function of the silica weight for LW and TW xerocomposites prepared with both silica precursors (LUDOX or TEOS) and for different $\mathrm{SiO}_{2}$ : $\mathrm{CaSiO}_{3}$ molar ratio.

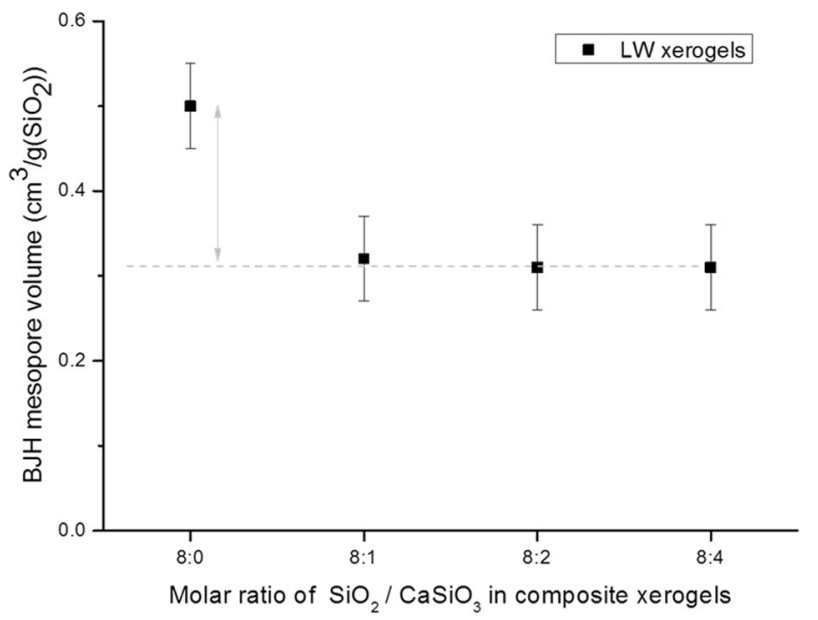

Fig. 9 Evolution of the BJH mesopore volume $\left(\mathrm{cm}^{3} / \mathrm{g}\right.$ of $\left.\mathrm{SiO}_{2}\right)$, as a function of the molar ratio $\mathrm{SiO}_{2}: \mathrm{CaSiO}_{3}$ in $\mathrm{LW}$ xerocomposites

For TW xerogels, we can observe (Fig. 8) an important decrease of the SSA from $294 \mathrm{~m}^{2} / \mathrm{g}\left(\mathrm{SiO}_{2}\right)$ in the case of the pure silica xerogel (TW8:0) to $\sim 174 \mathrm{~m}^{2} / \mathrm{g}\left(\mathrm{SiO}_{2}\right)$ for all other TW xerocomposites containing wollastonite (TW8:1, TW8:2, TW8:4). From SAXS results we deduced an increase of the size of the primary silica particles in TEOSwollastonite xerocomposites (radius $r_{2}=5.3 \mathrm{~nm}$ ) compared to a smaller size of primary particles obtained in pure TEOS xerogels $\left(r_{1}=3 \mathrm{~nm}\right)$. This result can explain the lower SSA value of $S_{2}=174 \mathrm{~m}^{2} / \mathrm{g}\left(\mathrm{SiO}_{2}\right)$ measured for TW8:2 xerocomposite compared to SSA value of $S_{1}=294 \mathrm{~m}^{2} / \mathrm{g}\left(\mathrm{SiO}_{2}\right)$ for pure TEOS TW8:0 (Fig. 8). As $S_{1} / S_{2} \sim r_{2} / r_{1} \sim 1.7$ we can consider that the origin of the SSA decrease in TW composites, comes from the silica-primary-particle size increase.

For LW xerogels, we observe in Fig. 8 that the SSA remains constant regardless of the molar fraction of fillers in the composite. This result is not surprising, as the silica network is formed by colloidal silica particles whose size does not depend on the synthesis conditions and gelification kinetics.

\subsection{Porous textural properties of LW xerogels}

The evolution of the mesoporous volume values $\left(V_{\mathrm{m}}\right.$ in $\mathrm{cm}^{3} /$ $\left.\mathrm{g}\left(\mathrm{SiO}_{2}\right)\right)$ obtained from the BJH method are shown in Fig. 9 for LW composite samples.

We can observe that the $\mathrm{BJH}$ mesopore volume remains constant, around $0.3 \mathrm{~cm}^{3} / \mathrm{g}\left(\mathrm{SiO}_{2}\right)$ for all xerocomposites, independently of the molar fraction of wollastonite in the composite. Nevertheless, this value is lower than the one obtained for pure LUDOX xerogel (LW8:0 sample), around $0.5 \mathrm{~cm}^{3} / \mathrm{g}\left(\mathrm{SiO}_{2}\right)$. In order to properly interpret this result, we show in Fig. 10 the BJH pore size distribution obtained for LW xerogels. 
The pore size distribution of all $\mathrm{LW}$ xerogels is very similar in term of width at half maximum, and centered at $\sim 30 \mathrm{~nm}$. This result indicates that the mesoporous texture of the LUDOX network remains the same at the end of the drying process, regardless of the presence and quantity of wollastonite fillers in the gel. Indeed, we believe that the mesopores in our xerocomposites are generated only by the drying of the silica gel phase, independently of the existence of micronic wollastonite fillers in the gel.

Pure LUDOX xerogel (LW8:0) contains the same quantity of LUDOX precursor as the LW xerocomposites. Because the pore size distribution of all LW xerogels is the same, we can then expect that the total mesopore volume of all of the LW series should also be constant. But this is not the case. The total mesopore volume of composite xerogels is $\sim 40 \%$ less than for the pure LUDOX xerogel (Fig. 9). We can then expect that for LW xerocomposites, a nonnegligible quantity of LUDOX colloidal particles do not participate in the formation of the silica gel network during the gel synthesis. This result is in accordance with the assumption that a significant fraction of LUDOX colloidal particles ( $40 \%$ of the total amount) could condense at the surface of wollastonite fillers at the beginning of the

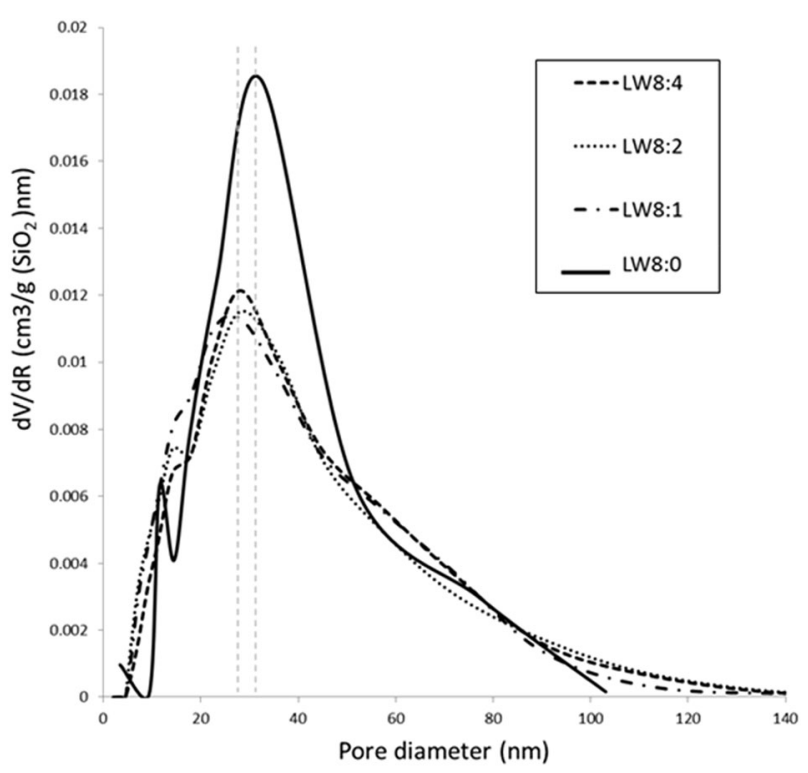

Fig. 10 Evolution of the pore size distribution in LW xerogels as a function of the molar ratio $\mathrm{SiO}_{2}$ (LUDOX): $\mathrm{CaSiO}_{3}$ gelification process. As a consequence, during the gelification process, there should be two options for colloidal particles: condensation between themselves in order to form the silica network (occurring for $\sim 60 \%$ of the total particles) and condensation of colloidal particles at the surface of wollastonite fillers (occurring for the remaining $40 \%$ ). Colloidal particles could then form a densely packed layer of silica spheres at the wollastonite fillers surface, contributing to the formation of small mesopores only (which do not significantly contribute to the total mesopore volume). Such a layer would then contribute to the shift in the average pore size to smaller values compared to pure LUDOX (LW8:0) xerogel. This small shift from $\sim 32 \mathrm{~nm}$ (LW8:0 sample) to $28 \mathrm{~nm}$ (other LW xerogels) is observed in Fig. 10.

A colloidal layer at the surface of fillers should on the contrary contribute to the SSA to the same extent as colloidal particles that form the gel network, in accordance with SSA results which are the same for pure LUDOX and composite LW xerogels (Fig. 8).

In order to better define the porous texture of LW xerogels and evaluate the macroporous/mesoporous proportion (see section Sample characterization), $\rho_{\mathrm{a}}$ and $\rho_{\mathrm{s}}$ densities and deduced total pore volume $\left(V_{\mathrm{T}}\right)$ values are indicated in Table 2.

From the calculated $V_{\mathrm{T}}$ values (Table 2), and the $\mathrm{BJH}$ mesopore volume measurements $\left(V_{\mathrm{m}}\right)$ (both $V_{\mathrm{T}}$ and $V_{\mathrm{m}}$ expressed in $\left.\mathrm{cm}^{3} / \mathrm{g}\left(\mathrm{SiO}_{2}\right)\right)$, we can then deduce the macropore volume $\left(V_{\mathrm{M}}\right)$ in our LW xerogels, using relation (2). $V_{\mathrm{T}}$ and $V_{\mathrm{m}}$ values and the deduced ratio of $V_{\mathrm{m}} / V_{\mathrm{M}}$ are indicated in Table 2 and Fig. 11.

These results confirm the absence of macropores in pure LUDOX xerogels, and their significant proportion $(>80 \%$ of the total volume) for the two studied LW composite. The macropore proportion seems to increase with the filler content.

\subsection{Porous textural properties of TW xerogels}

The evolution of the mesoporous volume values $\left(V_{\mathrm{m}}\right.$ in $\mathrm{cm}^{3} /$ $\left.\mathrm{g}\left(\mathrm{SiO}_{2}\right)\right)$ obtained from BJH method are shown in Fig. 12 for TW composite samples.

We can observe that the $\mathrm{BJH}$ mesopore volume remains constant for xerocomposites, around $1.27 \mathrm{~cm}^{3} / \mathrm{g}\left(\mathrm{SiO}_{2}\right)$,

Table 2 Values of $\rho_{\mathrm{a}}, \rho_{\mathrm{s}}$ densities and total pore volume $\left(V_{\mathrm{T}}\right), V_{\mathrm{m}}, V_{\mathrm{M}}$ and deduced ratio (\%) of mesopore /macropore volume of LW xerogels

\begin{tabular}{|c|c|c|c|c|c|c|}
\hline $\begin{array}{l}\text { Xerogel } \\
\text { sample }\end{array}$ & $\begin{array}{l}\text { Apparent density, } \\
\rho_{\mathrm{a}}\left(\mathrm{g} / \mathrm{cm}^{3}\right) \\
( \pm 10 \%)\end{array}$ & $\begin{array}{l}\text { Solid phase } \\
\text { density, } \rho_{\mathrm{s}}(\mathrm{g} / \\
\left.\mathrm{cm}^{3}\right)\end{array}$ & $\begin{array}{l}\text { Total pore } \\
\text { volume, } V_{\mathrm{T}} \\
\left(\mathrm{cm}^{3} / \mathrm{g}\right)( \pm 10 \%)\end{array}$ & $\begin{array}{l}\text { Calculated total pore } \\
\text { volume, } V_{\mathrm{T}}\left(\mathrm{cm}^{3} / \mathrm{g}\right. \\
\left.\left(\mathrm{SiO}_{2}\right)\right)( \pm 10 \%)\end{array}$ & $\begin{array}{l}\text { Mesopore volume, } V_{\mathrm{m}} \\
\left(\mathrm{cm}^{3} / \mathrm{g} \mathrm{SiO}_{2}\right) \text { and }(\% \\
\text { of mesopore })\end{array}$ & $\begin{array}{l}\text { Macropore volume, } V_{\mathrm{M}} \\
\left(\mathrm{cm}^{3} / \mathrm{g} \mathrm{SiO}_{2}\right) \text { and }(\% \text { of } \\
\text { macropores })\end{array}$ \\
\hline LW8:0 & 1.02 & $2[28]$ & 0.48 & 0.48 & $0.5(100)$ & $0(0)$ \\
\hline LW8:2 & 0.56 & 2.29 & 1.36 & 2 & $0.33(16)$ & $1.67(84)$ \\
\hline LW8:4 & 0.68 & 2.44 & 1.07 & 2.2 & $0.32(14)$ & $1.88(86)$ \\
\hline
\end{tabular}




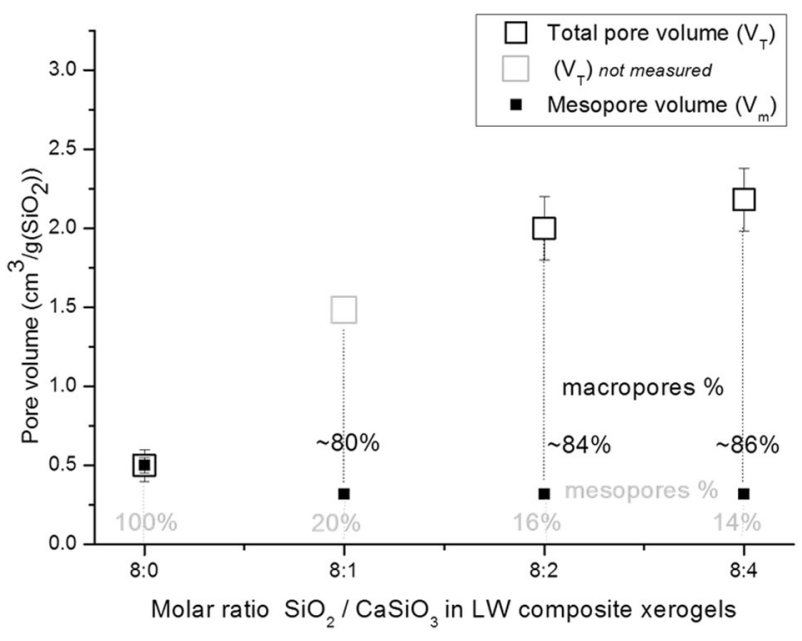

Fig. 11 Evolution of the relative mesoporous and macroporous volume percent (\%) in LW xerogels, as a function of the molar ratio $\mathrm{SiO}_{2}$ (LUDOX): $\mathrm{CaSiO}_{3}$

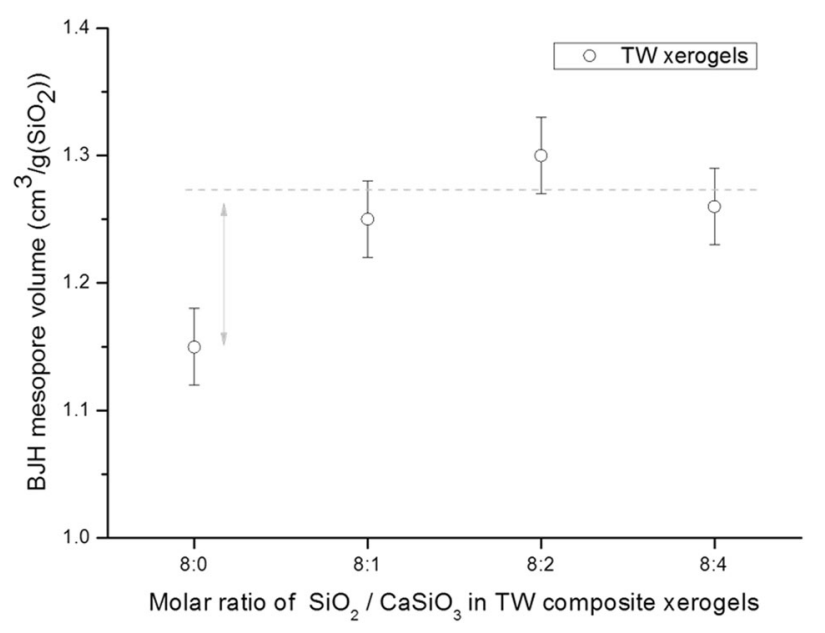

Fig. 12 Evolution of the $\mathrm{BJH}$ mesopore volume in $\mathrm{cm}^{3} / \mathrm{g}$ of $\mathrm{SiO}_{2}$, as a function of the molar ratio $\mathrm{SiO}_{2}: \mathrm{CaSiO}_{3}$ in $\mathrm{TW}$ xerocomposites with TEOS silica precursor

independent of the molar fraction of wollastonite. Nevertheless, this value is higher than the one obtained for pure TEOS xerogel (TW8:0 sample), around $1.15 \mathrm{~cm}^{3} / \mathrm{g}\left(\mathrm{SiO}_{2}\right)$. This result can be explained by pores having higher average size in composite TW xerogels. Fig. 13 clearly shows higher values of the average pore size (around $22 \mathrm{~nm}$ ) and broader pore size distribution for xerocomposites compared to a smaller average pore size value (around $12 \mathrm{~nm}$ ) and narrower pore size distribution for pure TEOS TW8:0 xerogel.

The final porous texture of the TW composite xerogel is then greatly influenced by the presence of wollastonite fillers. They induce an increase of the primary particle size in the sol, thus forming the silica gel with a likely less branched network with more space between silica branches, and thus, a higher permeability compared to the pure TEOS gel.

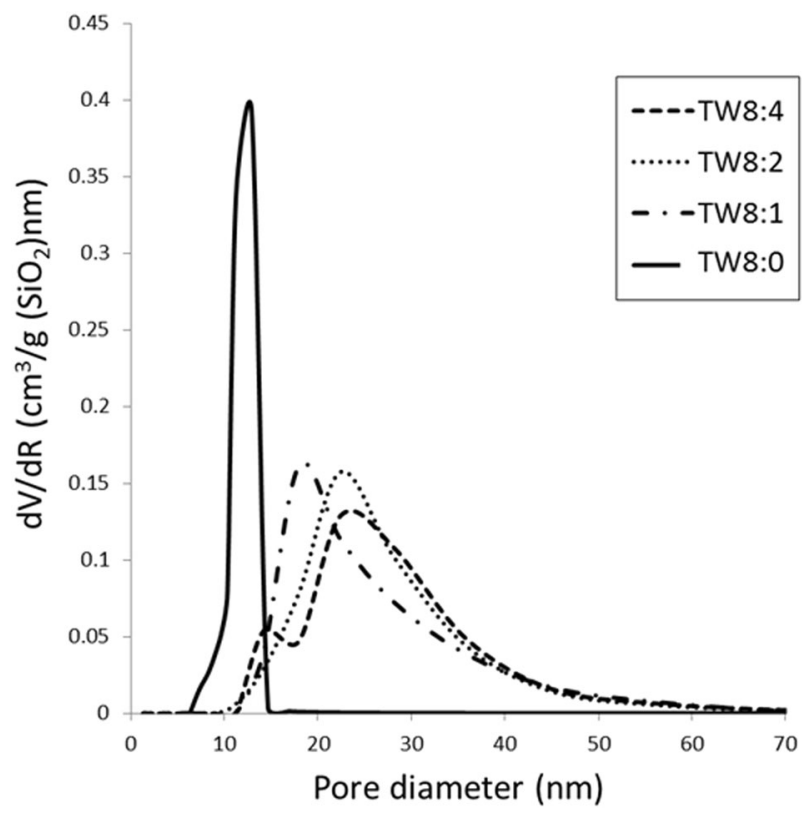

Fig. 13 Evolution of the mesopore size distribution in TW xerogels as a function of the molar ratio $\mathrm{SiO}_{2}$ (TEOS): $\mathrm{CaSiO}_{3}$

Such textural and structural changes could have a strong influence during the drying process where capillary forces involved in the gel shrinkage, and permeability, play an important role in the final porous texture of the dried xerogel [1].

In order to better define the porous texture of TW xerocomposites, and evaluate the macroporous/mesoporous ratio (see section Sample characterization), $\rho_{\mathrm{a}}$ and $\rho_{\mathrm{s}}$ densities and deduced total pore volume $\left(V_{\mathrm{T}}\right)$ values are indicated in Table 3.

From calculated $V_{\mathrm{T}}$ values (Table 3 ), and the $\mathrm{BJH}$ mesopore volume measurements $\left(V_{\mathrm{m}}\right)$, we can then deduce the macropore volume $\left(V_{\mathrm{M}}\right)$ in our TW xerogels, using relation (2). The $V_{\mathrm{T}}$ and $V_{\mathrm{m}}$ values, and deduced ratio of $V_{\mathrm{m}} /$ $V_{\mathrm{M}}$ are indicated in Table 3 and Fig. 14.

These results confirm the absence of macropores in pure silica (TW8:0) xerogels, and their existence for all TW composites. Therefore, an increase of the filler content causes an increase in macropore proportion. A similar tendency was observed in the case of the LW series.

\subsection{SEM on TW and LW xerocomposites}

Electronic microscopy images of both TW8:2 and LW8:2 xerocomposites are shown in Fig. 15 at different magnifications.

At the mm scale (Fig. 15, top) we can observe that the composite texture appears more compact and homogeneous in the case of LUDOX LW8:2 composite compared to TEOS TW8:2. The image at higher magnification confirms this observation (Fig. 15, middle): for LUDOX LW8:2 
Table 3 Values of $\rho_{\mathrm{a}}, \rho_{\mathrm{s}}$ densities and total pore volume $\left(V_{\mathrm{T}}\right), V_{\mathrm{m}}, V_{\mathrm{M}}$ and deduced ratio (\%) of mesopore/macropore volume of TW xerogels

\begin{tabular}{|c|c|c|c|c|c|c|}
\hline $\begin{array}{l}\text { Xerogel } \\
\text { sample }\end{array}$ & $\begin{array}{l}\text { Apparent density, } \\
\rho_{\mathrm{a}}\left(\mathrm{g} / \mathrm{cm}^{3}\right)( \\
\pm 10 \%)\end{array}$ & $\begin{array}{l}\text { Solid phase } \\
\text { density, } \rho_{\mathrm{s}}(\mathrm{g} / \\
\left.\mathrm{cm}^{3}\right)\end{array}$ & $\begin{array}{l}\text { Total pore } \\
\text { volume, } V_{\mathrm{T}}\left(\mathrm{cm}^{3} /\right. \\
\text { g) }( \pm 10 \%)\end{array}$ & $\begin{array}{l}\text { Total pore volume, } \\
V_{\mathrm{T}}\left(\mathrm{cm}^{3} / \mathrm{g}\left(\mathrm{SiO}_{2}\right)\right) \\
( \pm 10 \%)\end{array}$ & $\begin{array}{l}\text { Mesopore volume, } V_{\mathrm{m}} \\
\left(\mathrm{cm}^{3} / \mathrm{g} \mathrm{SiO}_{2}\right) \text { and }(\% \text { of } \\
\text { mesopore })\end{array}$ & $\begin{array}{l}\text { Macropore Volume } \mathrm{V}_{\mathrm{M}} \\
\left(\mathrm{cm}^{3} / \mathrm{g} \mathrm{SiO}_{2}\right) \text { and (\% of } \\
\text { macropores) }\end{array}$ \\
\hline TW8:0 & 0.62 & $2[28]$ & 1.12 & 1.12 & 1.15 (100) & $0(0)$ \\
\hline TW8:2 & 0.64 & 2.29 & 1.14 & 1.73 & $1.30(75)$ & $0.43(25)$ \\
\hline TW8:4 & 0.62 & 2.44 & 1.21 & 2.48 & $1.24(50)$ & $1.16(50)$ \\
\hline
\end{tabular}

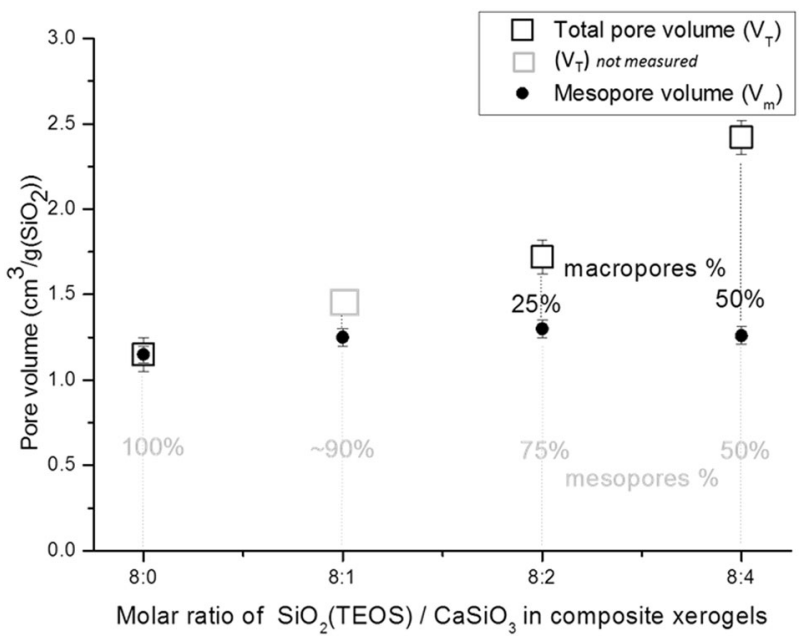

Fig. 14 Evolution of the relative mesopores and macropores volume percent $(\%)$ in xerocomposites, as a function of the molar ratio $\mathrm{SiO}_{2}$ (TEOS): $\mathrm{CaSiO}_{3}$

composites, wollastonite fillers seem to be well integrated into the silica matrix, and can then be distinguished with difficulty under the silica porous matrix. The TEOS TW8:2 composite exhibit a more granular, inhomogeneous texture, with connected aggregates composed of both wollastonite fillers and the silica porous matrix. At higher magnification (Fig. 15, bottom), we can observe individual and isolated wollastonite crystals. It appears that fillers in the LUDOX composite are totally recovered by the silica phase (Fig. 15 bottom, right). This could allow a better chemical compatibility with the silica clusters and explain its better integration into the silica porous matrix. This effect for LUDOX composites should create a more homogenous xerocomposite obtained after the gelation, drying, and shrinkage steps. This result is in accordance with $\mathrm{N}_{2}$ adsorption-desorption results which indicate that wollastonite fillers can be coated by a dense colloidal silica layer. Combining $\mathrm{N}_{2}$ adsorption-desorption and SEM experiments allow us to propose a textural model of the wollastonite surface: a multilayer but dense silica coating (with a probably rough surface) could be situated at the interface between the wollastonite surface and the silica porous matrix (Fig. 16). This layer should be formed during the early stage of the gelation process, before the formation of silica clusters. The latter are then formed in the sol. They finally condense to each other in order to create a 3D silica network. During this last gelation step, some silica clusters could also condense at the surface of wollastonite fillers covered by the silica-colloidal-layer (Fig. 16, right). Such a mechanism could explain why the densely packed colloidal interface should allow improving the chemical compatibility between wollastonite fillers and the silica porous matrix.

The wollastonite fillers in TEOS TW8:2 composite appear to be better defined (Fig. 15 bottom, left), with a shape close to the one obtained for pure wollastonite powders (Fig. 4). It appears that some wollastonite fillers can also be partially recovered by the porous silica phase (Fig. 15 bottom, left), as already observed by other authors [23]. At this stage, we cannot determine whether there exists a thin silica layer (at the molecular scale), resulting from the condensation of TEOS monomers at the wollastonite surface in TEOS TW composites.

Microscopy images at higher magnification (Fig. 15, middle and bottom) also show that wollastonite fillers in both LW and TW composites seem to be well dispersed, not aggregated but close, and possibly connected.

\subsection{Schematic representation of the structure and texture of $\mathrm{SiO}_{2}: \mathrm{CaSiO}_{3}$ xerocomposites}

For LW and TW xerocomposites, we found that both kinds of materials exhibit a porosity at two different scales: a porosity constituted of mesopores with size ranging from 2 to $100 \mathrm{~nm}$ and a macroporosity with pore size higher than $100 \mathrm{~nm}$ whose proportion is related to the wollastonite filler content in the composite. Both porosities textural characteristics should depend on the huge textural transformations of the composite gels which occur during the drying process. We propose then, in Fig. 17, a schematic representation of the evolution of the texture of our composites during the drying process.

We show in section Porous textural properties of LW xerogels that a certain amount of the silica precursor could be condensed on the surface of wollastonite fillers, especially for LW composites, while the remaining part of the precursor participate in the formation of the silica network in all the volume occupied by the liquid phase (see Fig. 
Fig. $15 \mathrm{SEM}$ images of $\mathrm{SiO}_{2}$ $\mathrm{CaSiO}_{3}$ xerocomposites: TW8:2 (left) and LW8:2 (right) at different magnification, $1 \mathrm{~mm}$, 100 , and $30 \mu \mathrm{m}$ scale
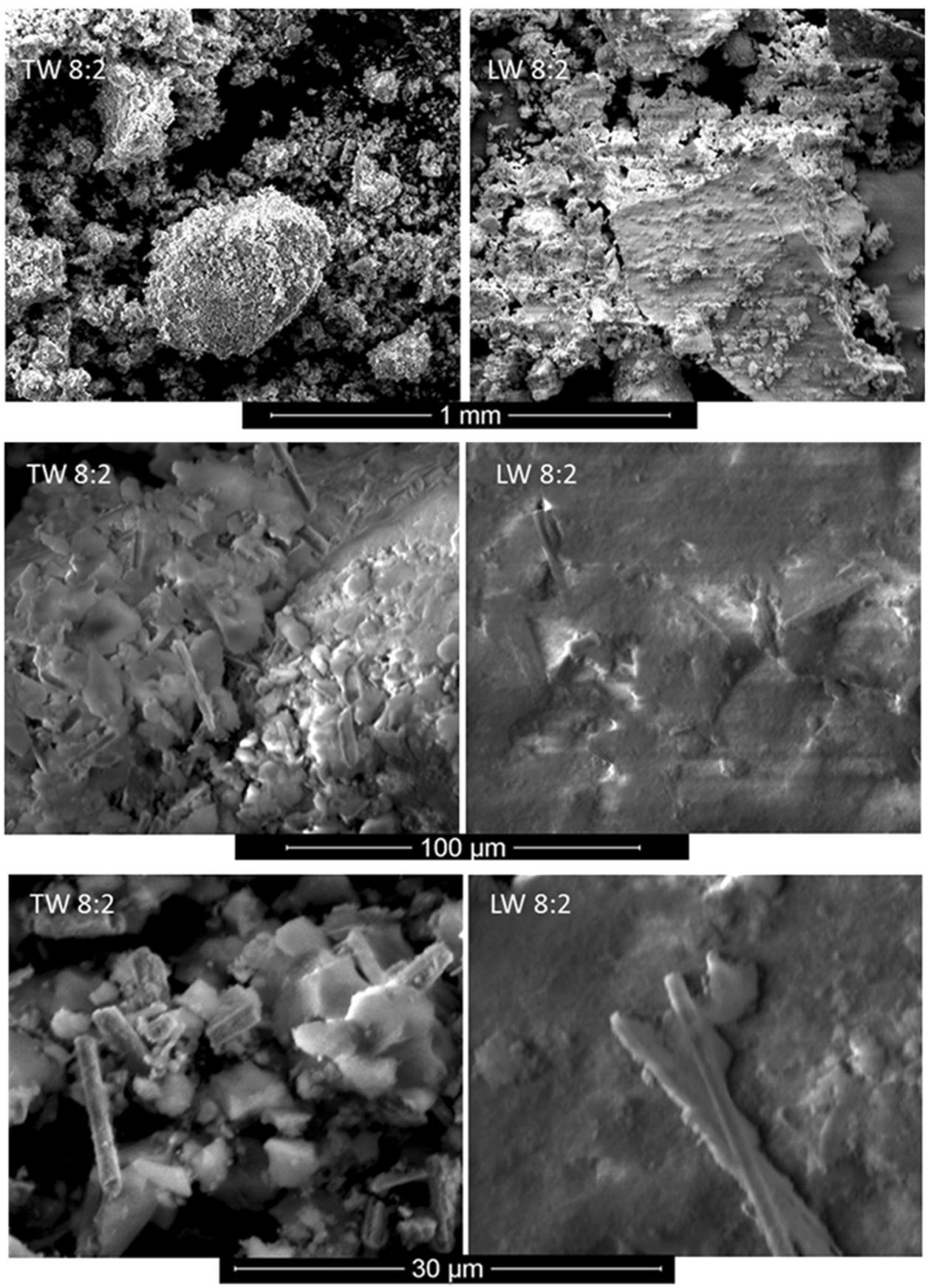

17a). During the first step of the classical drying process, evaporation of the liquid phase induces a progressive shrinkage of the wet gel volume. This shrinkage causes wollastonite fillers that are dispersed into the gel, to come closer together until they form a percolated filler network. When silica covers the surface of fillers, covalent bonds can be created by polycondensation reactions between fillers in contact, thus reinforcing the mechanical properties of the percolating filler network (see Fig. 17b). At this intermediate stage, the composite is still a wet gel. We can suppose that the percolating filler network can sufficiently reinforce the gel solid phase in order to resist capillary forces and avoid subsequent macroscopic shrinkage. On the contrary, the silica network should continue to shrink at a macroscopic constant volume, thus progressively forming the composite macroporosity (see Fig. 17c). At the end of the drying step, we obtain a material with porosity at two different scales: mesoporous silica clusters connected to a network of percolating fillers, and a macroporosity between silica clusters and fillers. From SAXS results which indicate the existence of larger secondary silica clusters, we can also imagine that during the second drying step, connected 
Fig. 16 SEM image of wollastonite fillers covered by silica in LW8:2 composite (left), and schematic representation of the dense coating of colloidal silica particles at the surface of wollastonite fillers in LUDOXwollastonite LW xerocomposites (right)
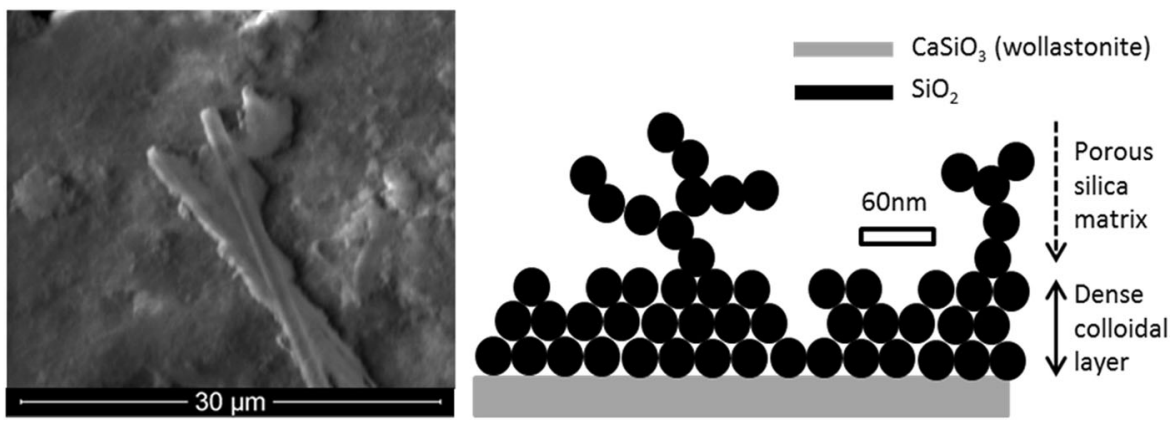

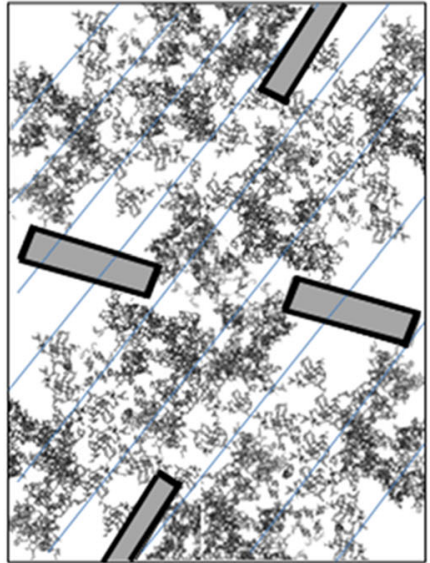

a)
$\mathrm{CaSiO}_{3}$

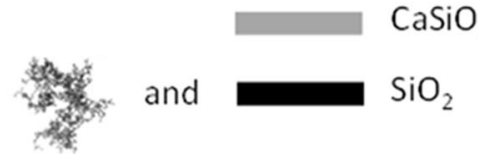

b) c)

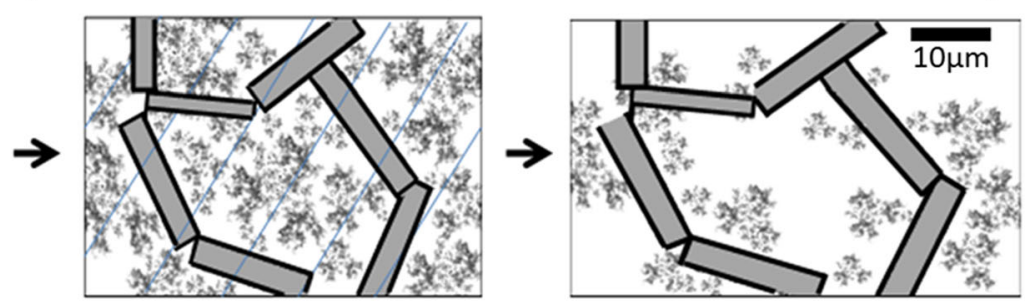

Fig. 17 Evolution of the porous texture of $\mathrm{SiO}_{2}-\mathrm{CaSiO}_{3}$ xerocomposites during the drying process. a Gel before drying. b First drying step with macroscopic shrinkage of the gel during drying. c Second drying step with shrinkage of the silica network at constant

groups of isolated silica clusters (secondary clusters in the range of $\sim 100-1000 \mathrm{~nm}$ ) are created. We believe that the increase of the filler quantity in the initial sol limits the macroscopic shrinkage of the gel during drying, thus giving xerogels with increasing macroporosity.

\section{Conclusion}

In this work, we show that homogeneous silica-wollastonite xerogels can be obtained from different silica precursors (LUDOX and TEOS). A fast gelification stage (<3 min) allows one to obtain a wet gel constituted of well-dispersed wollastonite fillers surrounded by a silica network formed during the sol-gel proces. Using SAXS, SEM, and $\mathrm{N}_{2}$ adsorption-desorption techniques, we show that the presence of wollastonite fillers in the sol have a great influence on the textural transformation occurring during the drying stage of the composite gel. As a result, we obtain xerocomposits with two-scale porosity: a mesoporosity induced by the silica network and a macroporosity whose macroscopic volume, formation of mesopores (intra silica primary and secondary cluster porosities), and macropores (inter silica secondary clusters-filler porosity)

proportion directly depends on the wollastonite filler proportion. A two-step drying mechanism is proposed in order to explain the formation of this macroporosity. A reinforced percolated filler network should be formed during the first drying stage, allowing an interruption of the macroscopic shrinkage. In the second stage, a partial shrinkage of the silica gel phase only at constant macroscopic volume permits the macroporosity formation. $\mathrm{N}_{2}$ adsorption-desorption results on silica-wollastonite xerocomposites were treated in an unusual way. By plotting BET surface and $\mathrm{BJH}$ volume as a function of the weight of silica only, we show that it is possible to demonstrate the existence of a dense colloidal silica layer at the surface of wollastonite fillers in LUDOX-wollastonite composites. This layer contains $\sim 40 \%$ of total silica amount and probably exhibit a rough surface at the $\mathrm{nm}$ scale, while the remaining $60 \%$ forms the silica porous network. We believe that such surface modified wollastonite fillers in $\mathrm{LUDOX} \mathrm{SiO}_{2}-\mathrm{CaSiO}_{3}$ xerocomposites, could favor nucleation and growth of calcite crystals, thus improving the wollastonite carbonation kinetics in aqueous media. 
Acknowledgements This article is a special tribute to the memory of our friend, colleague and mentor, Professor Jean Phalippou. The authors are also very grateful to David Bessières and Marina Hild ("Nanostructured materials for a sustainable development" FrancoVenezuelian PCP program) to Claude Castro-Gimenez from the French Embassy in Venezuela and the FONACIT (Venezuela) for their financial support and encouragements.

\section{Compliance with ethical standards}

Conflict of interest The authors declare that they have no conflict of interest.

\section{References}

1. Brinker C, Scherer G (1990) Sol-gel science. Academic Press Inc, New York

2. Aegerter M, Koebel M, Leventis N (2001) Aerogels handbook. Springer, New York

3. Calvo E, Menéndez J, Arenillas A (2011) In: Mohammed Muzibur Rahman (Ed.) Designing nanostructured carbon xerogels, nanomaterials. Intech Open, Spain. https://doi.org/10.5772/17157

4. Hasmy A, Jullien R (1995) Sol-gel process simulation by clustercluster aggregation. J Non-Cryst Solids 186:342-348

5. Teichner S, Nicolaon G, Vicarini G, Gardes G (1976) Inorganic oxide aerogels. Adv Colloid Interface 5:245-273

6. Fricke J (1992) Aerogels and their applications. J Non-Cryst Solids 147-148:356-362

7. Gronauer M, Fricke J (1986) Acoustic properties of microporous $\mathrm{SiO}_{2}$-aerogel. Acustica 59:177-181

8. Tsou P (1995) Silica aerogel captures cosmic dust intact. J NonCryst Solids 186:415-427

9. Qu R, Wang M, Sun C, Zhang Y, Ji C, Chen H, Meng Y, Yin P (2008) Chemical modification of silica-gel with hydroxyl- or amino-terminated polyamine for adsorption of Au (III). Appl Surf Sci 255:3361-3370

10. Teng Z, Han Y, Li J, Yan F, Yang W (2010) Preparation of hollow mesoporous silica spheres by a sol/gel emulsion approach. Microporous Mesoporous Mater 127:67-72

11. Woignier T, Phalippou J, Prassas M (1990) Glasses from aerogels Part 1: The synthesis of monolithic silica aerogels. J Mater Sci 25:3111-3117

12. Woignier T, Primera J, Lamy M, Fehr C, Anglaret E, Sempere R, Phalippou J (2005) The use of gels as host matrices for chemical species. Different ways to control the permeability and the mechanical properties. J Non-Cryst Solids 350:298-306

13. Reynes J, Woignier T, Phalippou J (2001) Permeability measurements aerogels: application to nuclear waste storage. J NonCryst Solids 285:323-327

14. Pierre AC (1998) Introduction to sol-gel processing. Kluwer Academic, Massachusetts

15. Woignier T, Phalippou J, Despetis F, Calas-Etienne S (2017) Aerogels processing. In: Klein L et al. (Eds) Handbook of sol-gel science and technology. Springer International Publishing, New York

16. Santos A, Toledo-Fernández J, Mendoza-Serna R, Gago-Duport L, De la Rosa-Fox N, Piñero M, Esquivias L (2007) Chemically active silica aerogel-wollastonite composites for $\mathrm{CO}_{2}$ fixation by carbonation reactions. Ind Eng Chem 46:103-107
17. Toledo-Fernández J, Mendoza-Serna R, Morales-Flórez V, De la Rosa-Fox N, Santos A, Piñero M, Esquivias L (2007) Aerogeles con aplicaciones en biomedicina y medioambiente. Bol Soc Esp Ceram V 46:138-144

18. Weissbart E, Rimstidt J (2000) Wollastonite: Incongruent dissolution and leached layer formation. Geochim Cosmochim Acta 64:4007-4016

19. Daval D, Martinez I, Corvisier J, Findling N, Goffe B, Guyot F (2009) Carbonation of Ca-bearing silicates, the case of wollastonite: experimental investigatins and kinetic modeling. Chem Geol 265:63-78

20. Daval D, Martinez I, Guinier J, Hellmann R, Corvisier J, Findling N, Dominici C, Goffe B, Guyot F (2009) Mechanism of wollastonite carbonation deduced from micro- to nanometer length scale observations. Am Mineral 94:1707-1726

21. Santos A, Ajbary M, Kherbeche A, Piñero M, De la Rosa-Fox N, Esquivias L (2008) Fast $\mathrm{CO}_{2}$ sequestration by aerogel composites. J Sol-Gel Sci Technol 45:291-297

22. Santos A, Ajbary M, Toledo-Fernández J, Morales-Flórez V, Kherbeche A, Esquivias L (2008) Reactivity of $\mathrm{CO}_{2}$ traps in aerogel-wollastonite composites. J Sol-Gel Sci Technol 48:224230

23. Morales-Flórez V, Santos A, Esquivias L (2011) Recent insight into xerogel and aerogel mineral composites for $\mathrm{CO}_{2}$ mineral sequestration. J Sol-Gel Sci Technol 59:417-423

24. Primera J (2002) Synthèse, Structure et Propriétés de Transport des Gels Composites $\mathrm{SiO}_{2}-\mathrm{SiO}_{2}$ : Etude expérimental et Simulation. Ph.D. thesis, Université de Montpellier 2, France.

25. Toki M, Miyashita S, Takeuchi T, Kanbe S, Kochi A (1988) A large-size silica glass produced by a new sol-gel process. J NonCryst Solids 100:479-482

26. Primera J, Woignier T, Hashmy A (2005) Ore structure simulation of gels with a binary monomer size distribution J Sol-Gel Sci Technol 34:273-280

27. Woignier T, Reynes J, Phalippou J, Dussossoy JL (2000) Nuclear waste storage in gel derived materials. J Sol-Gel Sci Technol 19:833-837

28. Marlière C, Woignier T, Dieudonné P, Primera J, Lamy M, Phalippou J (2001) Two fractal structures in aerogel. J Non-Cryst Solids 285:175-180

29. Woignier T, Primera J, Hafidi Alaoui A, Calas-Etienne S (2011) Mechanical behaviour of nano composite aerogels. J Sol-Gel Sci Technol 58:385-393

30. Ayral A, Phalippou J, Woignier T (1992) Skeletal density of silica aerogels determined by helium pycnometry. J Mater Sci 27:11661170

31. Brebler I, Kohlbrecher J, Thünemann (2015) SASfit: A tool for small-angle scattering data analysis using a library of analytical expressions. J Appl Crystallogr 48:1587-1598

32. Hasmy A, Anglaret E, Foret M, Pelous J, Jullien R (1994) Smallangle neutron-scattering investigation on long-range correlations in silica aerogels: simulation and experiments. Phys Rev B 50:6006-6016

33. Schaefer DW, Olivier BJ, Ashley CS, Richter D, Farago B, Frick B, Hrubesh L, Van Bommel MJ, Long G, Krueger S (1992) Structure and topology of silica aerogels. J Non-Cryst Solids 145:105-112

34. Vacher R, Woignier T, Pelous J, Courtens E (1988) Structure and self-similarity of silica-aerogels. Phys Rev B 37:6500-6503 


\title{
Correction to: Surface and porous textural properties of silica- wollastonite composites prepared by sol-gel process
}

\author{
Lismarihen Larreal de Hernandez ${ }^{1}$ Liz Anez-Borges ${ }^{1}$ - Thierry Woignier ${ }^{2,3}$ • Adil Hafidi Alaoui ${ }^{4}$. \\ Sylvie Calas-Etienne ${ }^{5}$. Florence Despetis ${ }^{5}$ - Laurent Bonnet ${ }^{5} \cdot$ Bruno Colaiocco $^{5}$ - Saïd Tahir ${ }^{5}$. \\ Philippe Dieudonné-George ${ }^{5}$
}

Published online: 28 March 2019

(c) Springer Science+Business Media, LLC, part of Springer Nature 2019

\section{Correction to: Journal of Sol-Gel Science and Technology;} https://doi.org/10.1007/s10971-018-4874-9

The original version of this article unfortunately contained a mistake. The Figure 1 was inadvertently duplicated in the source file, the same has been processed and published as Fig. 2. The correct Fig. 2 is given below. The original article has been corrected.

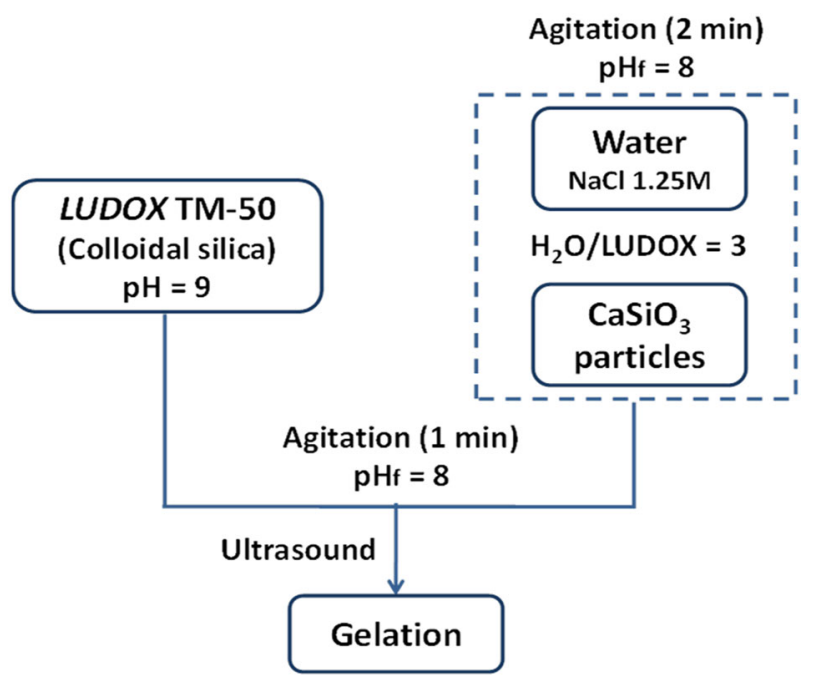

Fig. 2 Schematic representation of $\mathrm{SiO}_{2}-\mathrm{CaSiO}_{3}$ composite gel synthesis using the mineral precursor (LUDOX)

Institut Méditerranéen de Biodiversité et d'Ecologie, Campus Agro Environnemental Caraïbes, Le Lamentin, France

4 Laboratoire Génie civil et Mécanique, Université Abdelmalek Essaâdi, Faculté des Sciences et Techniques, Tanger, Morocco

5 Laboratoire Charles Coulomb (L2C), Univ. Montpellier, CNRS, Montpellier, France 